\title{
ESTRATEGIAS METACOGNITIVAS EN LA EDUCACIÓN CIENTÍFICA: CONTRIBUCIONES A SU INSERCIÓN EN EL CONTEXTO ESCOLAR
}

Recibido: 2020-01-20; Aceptado: 2020-11-10

\author{
Cleci Teresinha Werner da Rosa \\ cwerner@upf.br \\ http://orcid.org/0000-0001-9933-8834 \\ Universidade de Passo Fundo, Brasil \\ Marivane de Oliveira Biazus \\ marivanebiazus@gmail.com \\ https://orcid.org/0000-0003-4394-7061 \\ Universidade de Passo Fundo, Brasil
}

Resumen: El presente artículo parte de la necesidad de implementar prácticas educativas asociadas a las estrategias metacognitivas como forma de cualificar el aprendizaje de los estudiantes. El objetivo es discutir la comprensión de la metacognición como posibilidad para su asociación con el campo de la educación científica. Más específicamente, el texto, de naturaleza teórica, busca rescatar el concepto de metacognición frente a diferentes interpretaciones; reflexionar sobre la distinción entre los dominios cognitivos y metacognitivos; y discuta las estrategias metacognitivas y la importancia del profesor en este proceso. Además, el texto se ocupa de acenar para la necesidad de incluir una ampliación en los elementos metacognitivos. Particularmente en los trabajos de Monero y sus colaboradores. Finalmente, se señala el título de consideraciones finales, que el marco teórico emergido del estudio puede auxiliar los profesores y investigadores en la estructuración de prácticas pedagógicas destinadas a favorecer la activación del pensamiento metacognitivo y con esto permitir la cualificación del aprendizaje en el campo de la educación científica.

Palabra-clave: metacognición; maestro estratégico.

\section{ESTRATÉGIAS METACOGNITIVAS NA EDUCAÇÃO CIENTÍFICA: CONTRIBUIÇÕES PARA SUA INSERÇÃO NO CONTEXTO ESCOLAR}

Resumo: O presente texto parte da necessidade de implementar práticas educativas associadas às estratégias metacognitivas como forma de qualificar a aprendizagem dos estudantes. $\mathrm{O}$ objetivo está em discutir o entendimento de metacognição vinculada ao contexto educacional, apresentando as estratégias metacognitivas como possibilidade para sua associação ao campo da educação científica. De forma mais específica o texto, de natureza teórica, busca resgatar o conceito de metacognição frente a diferentes entendimentos; refletir sobre a distinção entre os domínios cognitivos e metacognitivos; e, discorrer sobre as estratégias metacognitivas e a importância do professor neste processo. Além disso, o texto se ocupa de acenar para a necessidade de incluir uma ampliação nos elementos metacognitivos tradicionalmente contemplados nos referenciais que discutem as estratégias metacognitivas, particularmente nos trabalhos de Monereo e colaboradores. Por fim, é apontado a título de considerações finais, que o arcabouço teórico emergido do estudo pode auxiliar os professores e pesquisadores na estruturação de práticas pedagógicas voltadas a favorecer a ativação do pensamento 
metacognitivo e com isso oportunizar a qualificação da aprendizagem no campo da educação científica.

Palavras-chave: metacognição; professor estratégico;

\title{
METACOGNITIVE STRATEGIES IN SCIENTIFIC EDUCATION: CONTRIBUTIONS TO THEIR INSERTION IN THE SCHOOL CONTEXT
}

\begin{abstract}
The present text of the need for implement educational practices associated with metacognitive strategies as a way to qualify students' learning. The objective is to discuss the understanding of metacognition linked to the educational context, presenting metacognitive strategies as a possibility for its association with the field of scientific education. More specifically the text, of a theoretical nature, it seeks to rescue the concept of metacognition in the face of different understandings; reflect on the distinction between cognitive and metacognitive domains; and discuss the metacognitive strategies and the importance of the teacher in this process. In addition, the text emphasizes the need to include an extension of the metacognitive elements traditionally contemplated in the references that discuss metacognitive strategies, particularly in the works of Monereo and collaborators. Finally, it is pointed out a final considerations, that the theoretical framework emerged from the study can help teachers and researchers in the structuring of pedagogical practices aimed at favoring the activation of metacognitive thinking and thereby enabling the qualification of learning in the field of scientific education.
\end{abstract}

Keywords: metacognition; strategic teacher.

\section{Introdução}

As dificuldades de aprendizagem têm sido apontadas como fator que contribui para que os estudantes se afastem da escola, particularmente em termos da educação básica (Cravino, 2004; Souza, 2006; Melo, 2004). Além disso, como lembram Pozo e Crespo (2006, p. 40) “os alunos não aprendem porque não estão motivados, mas, por sua vez, não estão motivados porque não aprendem". Seguem os autores mostrando que os alunos têm aprendido cada vez menos, mostrando-se desinteressados por aquilo que aprendem e afastando-se cada vez mais da Ciência.

Diante disso, temos a necessidade de buscar alternativas que contribuam para melhoria da aprendizagem dos jovens, favorecendo uma formação qualificada e voltada a autonomia intelectual, ao pensamento crítico e a capacidade de atuar e interferir na sociedade. Ou seja, urge como necessário ultrapassar o modelo de ensino tradicional presente nas escolas, particularmente no ensino de Ciências, melhorando as condições de aprendizagem dos conteúdos escolares. Formica, Easley e Spraker (2010) mostram que o ensino tradicional focado na exposição verbal do professor tem se tornado ineficaz para a aprendizagem, especialmente em relação a manter os alunos atentos e em provocar movimentos cognitivos que resultem na 
interação entre os conhecimentos prévios e os novos, considerado como fundamental para uma aprendizagem significativa. As metodologias alternativas que tem buscado superar essa visão do ensino tradicional focam como eixo central o deslocamento de ator principal do professor para o aluno. Nesse processo em que o aluno passa a ser o protagonista ao invés do professor, o foco está em oportunizar a ativação de mecanismos cognitivos potencializadores da aprendizagem e que possam contribuir para a autonomia intelectual, a formação de um pensamento cítrico e a capacidade de continuar aprendendo (Mota, \& Rosa, 2018).

A partir dessa necessidade surgem possibilidades de intervenções didáticas focadas no desenvolvimento destas capacidades, dentre as quais estão às vinculadas aos processos metacognitivos. Essa inferência toma por base o fato de que o uso do pensamento metacognitivo está relacionado diretamente ao reconhecimento dos estudantes sobre seus conhecimentos e suas habilidades frente ao desenvolvimento das ações. Isso representa uma alternativa promissora na busca por qualificar a aprendizagem, como salientado por Reif e Larkin (1991), Campanario e Otero (2000), Veemman (2006), Rosa (2011), Hinojosa e Sanmartí (2016) entre outros. De acordo com esses autores a tomada de consciência dos estudantes sobre seus próprios conhecimentos, tanto em termos dos conteúdos específicos quanto das tarefas propostas, bem como o controle autorregulador frente à execução dessas atividades, potencializam e favorecem a aprendizagem. Tais processos entendidos como metacognitivos são aqueles ativados pelo sujeito no momento em que identificam o seu próprio modo de pensar e regulam sua ação a partir disso. É estar consciente dos próprios processos cognitivos e de como eles se constituíram para a partir disso regular a ação a fim de obter êxito.

Desde os estudos desenvolvidos pela equipe de investigadores coordenados pela psicóloga americana Michelene Chi em 1982, o uso dos processos metacognitivos durante a aprendizagem em áreas como a Física, por exemplo, tem sido apontado como diferencial entre aqueles que apresentam facilidade na apropriação dos conteúdos (experts) e os que apresentam dificuldades na aprendizagem (novatos). A partir desses estudos, outros têm apontado que os alunos que compreendem melhor a estrutura de conceitos envolvidas na Física, que resolvem de forma mais eficientes os problemas e, portanto, apresentam melhores rendimentos acadêmicos, são os que recorrem ao pensamento de natureza metacognitiva (Reif, \& Larkin, 1993; Hennssey, 2003; Malone, 2008; Taasoobshirazi, \& Farley, 2013; Ryan et al., 2016). 
Taasoobshirazi e Farley (2013), por exemplo, destacam que os alunos que são experts em Física, são aqueles que usam mais estratégias orientadas para a meta de resolver problemas, apresentam um conhecimento maior e mais organizado, recorrem de forma mais eficaz ao pensamento metacognitivo, estão motivados para aprender e recebem mais estímulos sociais. Os autores ainda destacam que existem variáveis importantes, as quais contribuem para o sucesso dos experts, e que também os diferenciem dos considerados novatos na aprendizagem em Física. Segundo os autores, as variáveis referem-se a maneira como os problemas de Física são resolvidos, incluindo aspectos como: as estratégias reais de resolução de problemas usadas; a forma como os problemas são classificados, distinguindo os mais simples dos mais complexos; a amplitude e organização do conhecimento conceitual; o uso do pensamento metacognitivo; e, o uso de diagrama de corpo livre como parte da resolução dos problemas.

Particularmente vamos nos ater a variável vinculada ao pensamento metacognitivo, cuja evocação não representa um movimento espontâneo para muitos sujeitos, necessitando ser ativado por mecanismos externos. Em outras palavras, embora as pesquisas evidenciem os benefícios de sua utilização, particularmente em relação a aprendizagem em Física, grande parte dos estudantes não conseguem ativá-lo espontaneamente. Além disso, embora essa forma de pensamento seja algo interno do sujeito e sua ativação espontânea surgir em decorrência de um movimento interno das próprias estruturas de pensamento do sujeito, ela pode necessitar de estímulos externos, advindos de situações que a levem perceber a eficácia de pensar metacognitivamente.

Nesse contexto, em que essa forma de pensamento é entendida como inerente ao ser humano, identificamos que ela nem sempre é evocado espontaneamente, surgindo a necessidade de propor alternativas para estimular o seu uso pelos estudantes, de modo a mostrar os benefícios que ela representa. Sobre isso, temos que há uma crença consensual de que a prática da metacognição conduz a uma melhoria de toda a atividade intelectual e, portanto, a uma potencialização do processo de aprender (Lefebvre-Pinard, 1983; Borkowski, 1985; Campione, 1987). De acordo com os autores, a capacidade de identificar os próprios conhecimentos e o posterior gerenciamento consciente da ação, representam uma componente importante das performances de sucesso dos aprendizes. Nesse contexto, é salientado a capacidade de automonitoramento que contribui não só para melhorar a aquisição, mas, igualmente, para melhorar a generalização e a transferência do conhecimento e habilidades (Wang, \& Luidvall, 
1984; McCombs, 1988). Entretanto, as atividades metacognitivas contribuem não apenas o desenvolvimento dessas habilidades autorregulatórias, vinculada ao monitoramento, mas igualmente para o desenvolvimento do sentimento de domínio pessoal que, por sua vez, está relacionado a tomada de consciência dos sujeitos sobe seus próprios conhecimentos, como veremos mais adiante (Wang, 1983; McCombs, 1988).

A identificação da potencialidade do uso do pensamento metacognitivo, somado ao desejo por amenizar as dificuldades de aprendizagem dos estudantes, oportunizando que aprendam a aprender, emana o objetivo principal desse texto, estruturado na forma de um texto teórico: discutir o entendimento de metacognição vinculada ao contexto educacional, apresentando as estratégias metacognitivas como possibilidade para sua associação ao campo da educação científica. De forma mais específica pretendemos: resgatar o conceito de metacognição frente a diferentes entendimentos; refletir sobre a distinção entre os domínios cognitivos e metacognitivos; e, discorrer sobre as estratégias metacognitivas e a importância do professor neste processo.

Frente ao objetivo anunciado e suas especificidades, temos que o presente texto está estruturado na forma de seções, contendo inicialmente a descrição do conceito de metacognição e suas variações; na sequência, a distinção entre cognição e metacognição; e, na continuidade, se atém a discutir as estratégias metacognitivas, consideradas como o meio pelo qual podemos associar a ativação do pensamento metacognitivo às ações didáticas no campo da educação científica. Nesse sentido, o texto, ao final de sua incursão, aponta a necessidade de ampliar os aspectos metacognitivos que tradicionalmente tem sido associado as estratégias metacognitivas.

\section{Entendimento e variações do conceito de metacognição}

Em trabalhos anteriores relatamos o processo de construção do conceito de "metacognição" a partir de seu precursor, o psicólogo americano John Hurley Flavell, no final dos anos de 1969 e início dos anos de 1970 (Rosa, 2011; Rosa, \& Pinho-Alves, 2013; Rosa, 2014). Nas discussões partimos de que a construção dos primeiros entendimentos teve como pano de fundo as investigações sobre como os sujeitos usam seus processos de memória. Nesses estudos Flavell (1971; 1976), utiliza o termo "metacognição" para designar o modo como o sujeito conhece o que já conhece. Posteriormente, e em estudo com Henry Wellman (1977), Flavell sugere que o conhecimento metacognitivo se desenvolve por meio da consciencialização 
do sujeito sobre o modo como determinadas variáveis interagem no sentido de influenciar os resultados das atividades cognitivas.

Apesar do termo remontar as discussões já apresentadas por Piaget, a literatura atribui a Flavell o pioneirismo da sua utilização, pois é a partir dele que os investigadores, especialmente na educação e na psicologia cognitiva, passaram a se servir e adaptar esse construto aos seus campos. Reconhecidamente a metacognição, na forma como entendida por Flavell, tem suas bases na psicologia do desenvolvimento de Jean Piaget, sob a qual Flavell apoia suas discussões e estudos no campo da memória. Contudo, as definições, que foram sendo designadas ao termo nesses mais de quarenta anos de sua utilização pela acadêmica, trazem aproximações com teóricos como Lev Semionovich Vygotsky, por exemplo, sob uma perspectiva denominada de "metacognição social".

Essa, por sua vez, está voltada a reconhecer a importância de que os processos metacognitivos e aqui mais voltados aos autorregulatórios, surjam em decorrência de um convívio em grupo, em sociedade. Todavia, a exemplo do que veremos em Flavell, esta compreensão associa a metacognição ao objetivo da atividade a ser desenvolvida, vinculando a ela a oportunidade de que os sujeitos a compartilhar e explicitar com o outro suas ideias, terá mais chances de revisá-las e compreender as razões que o levaram a fazê-lo dessa forma (Chan, 2012).

Em Flavell, entretanto, é possível perceber a alusão à concepção piagetiana, embora a definição de "metacognição" do próprio autor tenha sofrido mudanças e ajustes ao longo de suas publicações. Dentre os marcos históricos está o publicado por Flavell em 1976 e intitulado "Metacognitive aspects of problem solving", no qual ele destaca que a metacognição

se refere ao conhecimento que se tem dos próprios processos e produtos cognitivos ou de qualquer outro assunto relacionado a eles, por exemplo, as propriedades relevantes para a aprendizagem de informações ou dados. [...] se refere, entre outras coisas, à avaliação ativa e consequente regulação e orquestração desses processos em função dos objetivos e dados cognitivos sobre o que se quer e, normalmente, a serviço de alguma meta ou objetivo concreto (Flavell, 1976, p. 232, tradução nossa).

Tal compreensão revela que a metacognição é integralizada por duas componentes: conhecimento do conhecimento e controle executivo e autorregulador (Rosa, 2011, p. 42). Dessas duas componentes, Flavell, em estudo com Wellman (1977), detalhou a primeira 
componente especificando as variáveis que interferem nessa tomada de consciência sobre os próprios conhecimentos; entretanto, a segunda não foi objeto de detalhamento de Flavell e levou a distintas interpretações e aproximações na literatura. Aliás, não apenas a especificação da segunda componente foi motivo de interpretações distintas como a própria definição de metacognição tem sido objeto de discórdia ente autores, como mostrou Muñoz (2019).

Essa falta de definição unânime entre os autores é, no entender de Weinert (1987), decorrente de o termo ser um construto de segunda ordem, uma vez que pensamentos sobre pensamentos, conhecimento sobre conhecimento ou reflexões sobre as ações necessitam vir acompanhados de uma especificidade para serem compreendidos. Dessa forma, o autor justifica o fato de que ainda não há um consenso sobre a definição de metacognição e sobre quais são as suas componentes.

Sobre isso, Veemann, Van Hout-Wolters e Afflerbach (2006, p. 3-4), retomando a definição de Flavell (1976), mostram que "sob a égide desta definição inclusiva, uma proliferação de termos metacognitivos se desenvolveu ao longo dos anos". Dentre esses termos, os autores mencionam um conjunto que estão vinculados à metacognição e que tem como cerne a definição original de Flavell. Nas palavras de Veemann, Van Hout-Wolters e Afflerbach (2006, p. 4, tradução nossa):

Crenças metacogntivas, percepção metacognitiva, experiências metacognitivas, conhecimento metacognitivo, sentimento de saber, julgamento da aprendizagem, teoria da mente, metamemória, habilidades metacognitivas, habilidades executivas, habilidades de ordem superior, metacomponentes, monitoramento de compreensão, estratégias de aprendizagem, estratégias heurísticas e autorregulação são vários dos termos que comumente associamos à metacognição.

Para os autores, essa gama de termos derivados do original tem levado a dispersar o foco da pesquisa em metacognição, demonstrando sua carência em termos de definição de um corpo teórico. Para eles, alguns termos se referem a conhecimentos mais gerais e a habilidades metacognitivas, enquanto outros abordam conhecimentos específicos para certas faixas etárias ou tipos de tarefas. Além disso, alguns se relacionam com processos cognitivos e metacognitivos (por exemplo, estratégias de aprendizagem e estratégias heurísticas), enquanto outros são puramente metacognitivos por natureza. Por fim, os autores reforçam a necessidade de realizar um estudo teórico mais profundo como forma de instituir uma teoria para esse constructo. 
No entanto, mesmo sem haver consenso sobre uma definição mais ampla em relação a metacognição, o campo tem avançado, particularmente em termos das pesquisas em educação científica, como mostrou Zohar e Barzilai (2013). De acordo com essas autoras, há um crescimento no interesse dos pesquisadores pelo termo, especialmente a partir dos anos 2000 e considerando o processo de ensino e de aprendizagem em Ciências.

O estudo das autoras, assim como o de Veemann, Van Hout-Wolters e Afflerbach (2006), aponta que, mesmo frente a essa diversidade de possibilidades de definições para a metacognição, o mais utilizado nas pesquisas no campo da educação em Ciências é a definição clássica de Flavell e seus colaboradores (1976, 1979, 1999), uma vez que ele vem servindo de base para muitos quadros de definições subsequentes. Portanto, como mencionado por Zohar e Barzilai (2013, p. 122, tradução nossa), "mesmo que muitos trabalhos divergem a partir do proposto por Flavell e seus colaboradores, existem, pelo menos, alguns aspectos comuns para comparações”. Situação que foi igualmente identificada e mencionado por Rosa (2011, p. 37) ao enfatizar a existência de um "núcleo coeso em torno do entendimento de metacognição como o pensamento sobre o próprio pensamento, ou a cognição da cognição”, o que remete à definição clássica de Flavell.

A partir dessa identificação, embora com diferenças em relação ao entendimento de metacognição, especialmente por conta das componentes e elementos que a constituem, há um consenso em termos da definição originalmente proposta por Flavell. Essa definição pode ser sintetizada pelo apresentado por Rosa (2011 p. 57, destaque da autora): “Metacognição é o conhecimento que o sujeito tem sobre seu conhecimento e a capacidade de regulação dada aos processos executivos, somada ao controle e à orquestração desses mecanismos".

$\mathrm{O}$ entendimento que vem em decorrência dessa definição infere o que Flavell já havia mencionado em 1976, que a metacognição é constituída por duas componentes: o conhecimento do conhecimento e o controle executivo e autorregulador. Todavia, nesse ponto iniciam as diferenças entre os autores, incluindo entre eles o próprio Flavell em seu artigo de 1979.

Dentre esses distintos arranjos temos estudos como o de Flavell e Wellman (1977) que centram sua análise no detalhamento do conhecimento metacognitivo associando-o aos processo de memória e recuperação da informação; o de Brown (1978) que volta sua análise ao plano executivo da ação, apontando a necessidade de planejar, monitorar e avaliar a ação; o de Flavell (1979) que direciona seu olhar para a constituição de um modelo no qual as experiências e o 
conhecimento metacognitivo são influenciados pelo objetivo e ações cognitivas, resultando que a ativação dessa forma de pensamento está associada a intencionalidade e aos caminhos executados pelos sujeitos, mas, sobretudo, aos sentimentos que os sujeitos apresentam em relação a esse objetivo e ação; o de Noël (1991) que enfatiza à tomada de consciência como um aspecto distinto da etapa do conhecimento metacognitivo, estruturando a metacognição a partir de três componentes (tomada de consciência - "processos metacognitivos"; julgamento "julgamento metacognitivo" ou "produto metacognitivo"; e, regulação dos mecanismos cognitivos - "decisão metacognitiva"); o de Nelson e Narens (1994) que compreende que a metacognição está envolvida por duas componentes (monitoramento e controle metacognitivo), sendo uma destinada a capacidade de observar, refletir, analisar, experienciar o andamento dos processos cognitivos e a outra a realizar estimativas por parte dos sujeitos sobre seu desempenho cognitivo e o que precisa ser feito para obter êxito na tarefa, estando associada ao julgamento que pode ocorrer em distintas fases da ação cognitiva (antes, durante ou depois).

Os exemplos mencionados ilustram diferentes entendimentos, todavia, há outros como o de Efklides (2006; 2008) que volta seu olhar para a importância das experiências metacognitivas associadas as emoções como desencadeadoras do processo de ativação do pensamento metacognitivo. Tais estudos no Brasil tem sido desenvolvido por Correa, Passos e Arruda $(2017$; 2018) que enaltecem a presença das experiências metacognitivas como integrante das ações de ativação do pensamento metacognitivo em contexto de aprendizagem.

Por fim, mencionamos o entendimento de Veenman (2011) que se assemelha ao de Rosa (2011) partindo igualmente dos estudos de Flavell (1976; 1979) e Brown (1978), enfatiza a metacognição como o conhecimento e a regulação das atividades cognitivas nos processos de aprendizagem, distinguindo o primeiro como conhecimento metacognitivo e o segundo como habilidades metacognitivas, como mencionado na seção anterior. Os estudos de Veenman e colaboradores têm se centrado mais em explorar as habilidades metacognitivas e enfatizam a presença dos elementos planificação, monitoramento e avaliação, a exemplo do proposto por Brown.

Foge ao escopo do presente texto apresentar todas as interpretações/definições existentes, assim como detalhar cada um desses entendimentos, o que demandaria um texto específico. O olhar deste texto está voltado a importância de que no contexto escolar os 
professores se preocupem em explicitar momentos de evocação dessa forma de pensamento, o que pode ser traduzido pela utilização de estratégias metacognitivas.

\section{Cognição $X$ Metacognição}

A identificação da compreensão de metacognição a partir de suas origens e a demarcação de que, embora ela tenha diferentes possibilidades de estruturação, pode ser utilizada no contexto escolar em função de sua definição mais geral, leva a discussão das "estratégias metacognitivas". Ao adotarmos como uma estratégia a metacognição pode atuar como favorecedora da aprendizagem, impulsionando a ativação de mecanismos que favorecem, além da tomada de consciência dos sujeitos sobre seus próprios conhecimentos - ainda pouco explorado nas ações didáticas, o gerenciamento sobre suas ações - que tem se revela mais presente, com veremos.

Sua discussão em termos da associação com o contexto escolar, requer antes uma retomada entre o que se entende por cognição, no sentido de distingui-la da metacognição. Iniciamos mencionando que tradicionalmente a imagem da cognição está restrita aos processos e produtos mais chamativos e inequivocamente "inteligentes" da mente humana, ou seja, são os processos que constituem as imagens que evocam essa mente humana. Dessa forma, a cognição estaria relacionada ao que Flavell, Miller e Miller (1999, p. 9) entendem como processos mentais superiores correspondendo ao

conhecimento, a consciência, a inteligência, o pensamento, a imaginação, a criatividade, a geração de planos e estratégias, o raciocínio, as inferências, a solução de problemas, a conceitualização, a classificação e a formação de relações, a simbolização e, talvez, a fantasia e os sonhos.

Continuam os autores, mencionando que contemporaneamente, são acrescentados a essa definição clássica outros processos, como "os movimentos motores, a percepção, as imagens mentais, a memória, a atenção e o aprendizado, além de variações sociopsicológicas” (p. 9). Todavia, os mesmos autores mencionam que para uma concepção ampla do que é a cognição, é necessário compreender também a complexa inter-relação entre aspectos da cognição, considerando o funcionamento cognitivo efetivo em tempo real. Os processos cognitivos têm papel vital para a manutenção e desenvolvimento uns com os outros, numa concepção de interação mútua. Nesse sentido, ao associar a relação entre processos cognitivos e 
conhecimento, o modo como as pessoas elaboram os conceitos ou como os classificam pode influenciar, em alguma medida, no raciocínio e, consequentemente, na forma como percebem as coisas. Os autores comparam a mente a uma máquina, pois ela é formada por inúmeras partes interligadas que, juntas, formam "um sistema de componentes em interação, organizada de forma complexa" (Flavell, Miller, \& Miller, 1999, p. 10).

De acordo com esses mesmos autores, a metacognição, de forma geral, está relacionada a "qualquer conhecimento ou atividade cognitiva que toma como seu objeto, ou regula, qualquer aspecto de qualquer iniciativa cognitiva" (p. 125). Dessa forma, a metacognição está fundamentada na cognição, pois é muito difícil ter um conhecimento metacognitivo adequado das competências de um domínio sem conhecimento substancial, ou seja, cognitivo, específico do domínio, tal como o conhecimento sobre conceitos e teorias relevantes num domínio, sobre dificuldades intrínsecas de um domínio e sobre o que é irrelevante.

Veenman, Van Hout-Wolters e Afflerbach (2006) destacam que grande parte das conceituações a respeito da metacognição segue a perspectiva da cognição de ordem superior à cognição. Nessa perspectiva, há um agente de ordem superior, o qual supervisiona e governa o sistema cognitivo ao mesmo tempo que faz parte dele. No entanto, os autores ressaltam que não é possível "dividir o eu em dois, dos quais um pensa enquanto o outro o observa pensando" (2006, p. 5). Visto dessa forma, a metacognição seria o conjunto de autoinstruções para regular o desempenho da tarefa, e a cognição seria um veículo dessas autoinstruções, de modo que um se conecta ao outro, tornando-se difícil separá-los ou colocá-los de formas distintas, já que um está relacionado ao outro.

Os autores mencionam ainda que, em algumas situações, é possível observar a metacognição quando os alunos verbalizam autoinstruçoes, "como isso é difícil para mim, vamos fazê-lo passo a passo ou espere, eu não sei o que essa palavra significa" (Veenman, Van Hout-Wolters, \& Afflerbach, 2006, p. 6). Seguem os autores especificando que nem sempre é possível observar de forma clara ou explícita os processos metacognitivos utilizados pelo aluno na realização da tarefa ou, ainda, podem se tratar apenas de processos cuja natureza é cognitiva. Nesse sentido, as pesquisas futuras precisam mostrar de forma mais precisa "o conhecimento metacognitivo explicitamente verbalizado nas autoinstruções - atividades cognitivas que são indicativas de metacognição e atividade puramente cognitiva" (p. 6). 
Kuhl e Kraska (1989) defendem que, em um nível mais superficial, parece ser mais simples distinguir a cognição da metacognição. Segundo os autores, a cognição está relacionada à representação dos objetos e fatos, num sentido mais específico, e a qualquer tipo de representação da informação proveniente do meio, num sentido mais amplo. Já a metacognição está relacionada ao conhecimento do próprio conhecimento, à avaliação, à regulação e à organização dos próprios processos cognitivos. Brown (1978), por sua vez, destaca que, dentro dos inúmeros problemas relacionados à formulação de uma teoria sobre a metacognição, encontra-se essa distinção entre cognição e metacognição. Contudo, lembra que um bom exemplo dessa relação está na habilidade para ler um texto e na habilidade para monitorar a compreensão desse texto. A primeira habilidade está mais relacionada ao campo da cognição, enquanto a segunda se situa na metacognição.

A dificuldade em distinguir o que pertence a cada domínio é compartilhada por Flavell (1979), ao mencionar que aparentemente algo que possa estar relacionado à monitoração da aprendizagem, por exemplo, pode estar a serviço do pensamento cognitivo. Nesse mesmo sentido, Livingston (2003) apoiando-se em Flavell (1979) não diferencia o conhecimento metacognitivo do cognitivo, mas ressalta que a identificação de cada um estaria na forma como uma informação é utilizada. Segundo ela, deve-se considerar que "a metacognição é referida como 'pensar sobre o pensar' e envolve a supervisão se uma meta cognitiva foi cumprida" (Livingston, 2003, p. 4, tradução nossa).

Tal distinção pode ser utilizada para determinar que uma situação se aproxima de um processo cognitivo ou de um processo metacognitivo. Ou seja, uma mesma situação pode ser entendida como demanda cognitiva ou metacognitiva, dependendo dos recursos empregado pelo indivíduo para alcançar o objetivo.

Livingston (2003, p. 5, tradução nossa), seguindo o mencionado por Flavell, Miller e Miller (1999) coloca que:

As estratégias metacognitivas e cognitivas podem sobrepor-se na medida em que a mesma estratégia, como questionamento, poderia ser considerada tanto como uma estratégia cognitiva ou uma metacognitiva, dependendo do que o objetivo do uso dessa estratégia pode ser.

De forma a exemplificar, a autora cita que, durante uma leitura, quando o sujeito levanta questionamentos como uma forma de estratégia para compreendê-lo, estes podem fornecer 
conhecimento cognitivo, ou, por outro lado, podem representar uma forma de monitorar o que foi lido, ou seja, um conhecimento metacognitivo. Isso revela que as estratégias "estão intimamente ligadas e dependentes umas das outras, qualquer tentativa de analisar um sem reconhecer o outro não daria uma imagem adequada" (Livingston, 2003, p. 5, tradução nossa).

Hacker (1998), com o objetivo de clarear essa distinção, menciona outro fator como relevante, que é a identificação da fonte. Para ele, o que se situa no campo da cognição seriam as coisas do mundo real e suas imagens mentais, ou seja, os objetos, pessoas, eventos etc.; enquanto as relacionadas à metacognição estariam vinculadas às habilidades que os sujeitos apresentam para lidar com essas entidades. De forma mais clara, o autor pontua que os pensamentos metacognitivos não brotam da realidade externa imediata de uma pessoa; em vez disso, sua fonte está ligada às próprias representações mentais internas daquela realidade, que podem incluir o que se sabe sobre essa representação interna, como ela funciona e como se sente sobre ela.

Considerando os estudos mencionados, observamos que há um consenso entre os pesquisadores sobre a importância da diferenciação entre o que se situa na dimensão cognitiva e o que pertence a metacognitiva. Também é evidente nos estudos, que essa tarefa não é fácil, uma vez que se trata de conceitos complexos em que uma mesma situação pode se revelar no campo da cognição e em outro momento da metacognição. A utilização de distintas estratégias para cada uma das situações pode ser uma forma de diferenciação entre o que é cognitivo e metacognitivo, todavia, elas estariam centradas na intencionalidade de quem utiliza ou propõe as estratégias e não em uma situação natural de espontaneidade. Considerando a intencionalidade podemos inferir que as estratégias orientadas pela cognição seriam aquelas utilizadas pelo sujeito para resolver um problema, sem a associação de momentos de

identificação de seus próprios conhecimentos, planificação das ações ou mesmo o acompanhamento e avaliação da ação executada, o que caracterizaria uma estratégia de natureza metacognitiva.

\section{Estratégias metacognitivas no contexto escolar: entendimentos conceituais}

De acordo com Camargo e Dias (2003), o termo "estratégia" tem sua origem a aproximadamente, 3000 anos e está associado a táticas desenvolvidas para alcançar vitórias. Desde então o termo vem sendo utilizado e passou a ser empregado em diferentes setores como 
a política, o financeiro, comércio, entre outros, cuja definição passou a compreender ações que devem ser realizadas para alcançar uma meta ou um objetivo. Ao adicionarmos a aprendizagem ele fica delineado como sendo um conjunto de ações que são realizadas para alcançar o objetivo de aprendizagem.

No caso das estratégias de aprendizagem, Figueira (2006), destaca que há um grande número de definições e interpretações do termo em se tratando do contexto escolar, mas de forma geral e consensual entre os pesquisadores, pode-se definir "como comportamentos e pensamentos que o sujeito pode utilizar no decurso da aprendizagem e que influenciam a forma como processa a informação, através da ativação, controle e regulação dos processos cognitivos" (p. 7). Desta forma, as estratégias de aprendizagem seriam as ações e os meios pelos quais o sujeito aprende.

Monereo (1990), considerando também diferentes visões, coloca que as estratégias para aprendizagem são comportamentos planejados utilizados para a seleção e organização de mecanismos cognitivos, afetivos e motores para enfrentar situações problemáticas, globais ou específicas, de aprendizagem. Ainda, segundo o autor, as estratégias têm uma função primária em qualquer processo de aprendizagem, cujo papel é "facilitar a assimilação da informação que chega do lado de fora ao sistema cognitivo do sujeito, que envolve gerenciar e monitorar a entrada, rotulagem-categorização, armazenamento, recuperação e saída de dados” (p. 4).

As estratégias de aprendizagem podem envolver operações cognitivas e metacognitivas, que são adequadas às exigências de diferentes situações em que são realizadas deliberada e conscientemente para alcançar os objetivos de aprendizagem da maneira mais eficiente possível, como mencionado na seção anterior. Rosa $(2011$; 2014) coloca que as estratégias de aprendizagem cognitivas seriam aquelas que tem o objetivo de auxiliar na organização do conhecimento, como por exemplo, elaborar tópicos, sublinhar, estabelecer redes de conceitos entre outros, e as estratégias de aprendizagem metacognitivas estariam envolvidas com o planejamento, a monitoração e a regulação do próprio pensamento. Infere-se, portanto, que as estratégias metacognitivas constituem um suporte para estratégias cognitivas.

Segundo a autora, muitas pesquisas têm apontado que o uso de estratégias de aprendizagem favorece uma aprendizagem significativa, uma vez que desafia e oportuniza o aluno a construir o seu próprio conhecimento, através da mediação do professor. A autora ainda enfatiza que as estratégias de aprendizagem que se utilizam de processos metacognitivos 
representam um aprendizado mais rico, e "conduzem os aprendizes a entender não apenas os conhecimentos específicos, mas também os mecanismos internos que lhes permitiram a construção desses conhecimentos" (ROSA, 2014, p. 82).

Retomando a perspectiva de Monereo e agora referindo-se a seus estudos desenvolvido com colaboradores, inferimos que as estratégias de aprendizagem são definidas como "processos decisórios (conscientes e intencionais) nos quais o aluno escolhe e recupera, de forma coordenada, o conhecimento necessário para completar uma demanda determinada ou objetivo, dependendo das características da situação educacional em que a ação ocorre" (Monereo et al., 2011, p. 27, tradução nossa). Isso significa que um estudante para utilizar uma determinada estratégia de aprendizagem, precisa planejar, regular e avaliar as suas ações de forma a adaptá-la ao seu conhecimento e as demandas da tarefa e do contexto.

Visto dessa forma, o aluno não deve apenas conhecer ou utilizar um procedimento para resolver uma tarefa específica, repetindo as etapas corretas de sua utilização. Mas deve também ser capaz de avaliar as vantagens de um procedimento em relação a outro, para aquela atividade específica e refletir em como essa técnica ou procedimento pode ser útil na resolução da tarefa. Nesse processo, é importante destacar que a consciência de ambos os conteúdos de conhecimento das estratégias empregadas e sua eficácia (regulação da cognição) vêm como resultado da reflexão consciente realizado durante o processo de ensino.

Nesse sentido, Monereo et al. (2011, p. 23, tradução nossa) fazem uma distinção entre o que seria uma estratégia de aprendizagem e o uso apenas de um procedimento ou técnica: “As técnicas podem ser utilizadas mais ou menos mecanicamente, sem que seja necessário que para a sua aplicação exista uma finalidade de aprendizagem por parte do usuário". Segundo os autores, as técnicas, assim como os procedimentos, seriam elementos subordinados ao uso das estratégias. Segue esses mesmos autores, “as estratégias, por outro lado, são sempre conscientes e intencional, visando um objetivo relacionado à aprendizagem” (p. 23, tradução nossa). Os autores ressaltam que, muitas vezes, os termos "técnicas" e "procedimentos" aparecem como sinônimos, mas é necessário distingui-los para que se possa concentrar nos objetivos de uma aprendizagem.

Nessa perspectiva, Monereo et al. (2011) afirmam que o interesse dessa forma de aprendizagem não está apenas em transmitir certos procedimentos, para que o aluno possa realizar determinada tarefa, mas sim que ele possa construir um conhecimento próprio sobre o 
uso adequado desses procedimentos. Essa construção pessoal, que deve partir do conhecimento já adquirido, está intimamente relacionada à reflexão ativa e consciente sobre quando e por que um procedimento ou técnica é apropriado, ou em relação aos requisitos que tanto o conteúdo quanto a situação de ensino possam exigir ao resolver a tarefa.

Os autores mencionados, utilizando-se de uma analogia, apresentam como essa estratégia de aprendizagem seria operacionalizada na execução de uma tarefa. Suponha que o objetivo da tarefa seja a de cortar uma peça (uma manga, um dossel e o vidro de uma janela, por exemplo) a partir de determinado material (um pedaço de pano, a superfície de um tubo e um vidro). Para cada situação, os profissionais precisam tomar decisões a respeito de qual processo devem utilizar para realizar o corte, ou seja, utilizar uma estratégia. Nesse caso, precisam levar em consideração o material a ser cortado (isso representa o conteúdo); escolher a ferramenta adequada (aqui seria o tipo de procedimento a ser utilizado); alguns materiais precisam de ferramentas específicas (procedimentos específicos de uma disciplina); a qualidade e complexidade do produto a ser desenvolvido (qualidade e complexidade da aprendizagem); a habilidade do profissional em manusear as ferramentas (por exemplo, para sintetizar um texto pode ser utilizado um resumo, um esquema, uma tabela). Também é preciso considerar as condições externas, como o tempo disponível, as preferências do cliente (no caso, as preferências do professor), o trabalho em equipe ou individual, a aproximação que cada um tem com o tipo de tarefa, entre outros aspectos (Monereo et al., 2011).

A partir de exemplos como o mencionado, os autores apontando que, para um aluno utilizar estratégias de aprendizagens, podemos inferir três objetivos principais, que devem ser desenvolvidos a fim de que ele possa aprender a ser estratégico: o primeiro objetivo é melhorar o conhecimento declarativo e processual (conhecimentos específicos, disciplinares e interdisciplinares); o segundo e o mais desafiador consiste em aumentar a consciência do aluno sobre as operações e decisões que toma quando aprende um conteúdo ou resolve uma tarefa; o terceiro é o necessário para promover o conhecimento e a análise das condições exigidas para a resolução de um certo tipo de tarefa ou a aprendizagem de um conteúdo específico, ou seja, conseguir transferir as estratégias usadas para novas situações, por meio do reconhecimento de condições similares em uma nova situação.

Esses três objetivos podem ajudar os alunos a aprender de forma mais consciente, analisando e monitorando suas atividades de aprendizagem, especialmente no momento em que 
planejam sua ação durante a sua execução e também durante a avaliação do executado nessa ação. Para promover tais objetivos, Monereo et al. (2011, p. 32, tradução nossa) destacam que

o ensino de estratégias está ligado à metodologia de ensino-aprendizagem utilizada pelo professor para favorecer uma dinâmica em que a premissa "refletir ou pensar em voz alta sobre como pensa-se ao aprender", ocupa um lugar privilegiado em cada uma das atividades escolares.

Nesse contexto, a ação do professor é fundamental, pois é ele quem planeja as atividades, repassa aos alunos, avalia e fornece certos mecanismos de ajuda pedagógica que podem favorecer ou não o aprendizado dessas estratégias. O professor, nesse contexto, representa o profissional que possui a teoria, a sistematização metodológica e a intencionalidade educacional e tem a função de mediação, na qual recorre a mecanismos de orientação capazes de guiar o aluno para alcançar seus objetivos de aprendizagem.

\section{Estratégias metacognitivas no contexto escolar: o papel do professor}

Frente a esse papel central do professor no processo de aprendizagem, a escola torna-se o local ideal para ensinar aos alunos como utilizar as estratégias de aprendizagem, pois dificilmente estratégias elaboradas, por exemplo, compreensão, leitura ou resolução de problemas são desenvolvidas sem orientação. Por outro lado, é preciso considerar que o ensino ineficiente pode fazer com que os alunos não desenvolvam estratégias de aprendizagem adequadas que, posteriormente, podem se revelar um obstáculo à construção do conhecimento por parte dos alunos.

A respeito disso Monereo et al. (2011) reconhecem que, para os alunos utilizarem as estratégias de aprendizagem, é necessário que o professor também o faça, sendo "estratégico", ou seja, ele deve conhecer e usar estratégias de aprendizagem na estruturação das ações didáticas. Monereo e Clariana (1993) definem um "professor estratégico" como aquele que apresenta competências reguladoras que tornam possíveis o planejamento, o monitoramento e a avaliação dos seus processos cognitivos, tanto no momento da aprendizagem dos conteúdos a serem ensinados quanto no momento que passa a ensiná-los para os alunos.

Todavia, é necessário considerar que as estratégias precisam ser aprendidas e isso não é diferente quando se trata do professor. Conforme os autores, é necessário que os professores sejam "aprendizes" no seu próprio processo de formação, obtendo o conhecimento "declarativo" 
(sobre os objetos, propriedades, relações gerais e específicos), o conhecimento procedimental (sobre como ele aprende) e, acima de tudo, o conhecimento condicional (sobre quando e para que propósito utilizará o conteúdo aprendido), para poder tomar decisões mais apropriadas na organização e preparo das aulas e no momento de ensiná-lo, formando estudantes estratégicos. Para aprender a ser estratégicos, Monereo et al. (2011, p. 54, tradução nossa) especificam que há dois requisitos fundamentais que devem ser considerados:

O primeiro refere-se à reflexão sobre o estado do próprio conhecimento e habilidades, e envolveria a capacidade de pensar e responder perguntas como: Sou capaz de escrever sinteticamente as ideias que um professor expõe? Eu posso lembrar depois de uma semana de aula os nomes e sobrenomes de todos os meus alunos? Eu tenho os recursos necessários para gerenciar adequadamente uma atividade? Sei como expandir meu conhecimento sobre minha especialidade? Esta avaliação do conhecimento ou habilidades em uma situação hipotética, ou uma autoimagem cognitiva, adquire um papel relevante quando se trata de prever o sucesso antes de uma tarefa específica e permite tomar decisões que facilitem a realização de um objetivo. $O$ segundo requisito refere-se à capacidade do aprendiz de regular seu desempenho para executar uma tarefa ou resolver um problema, e envolve a capacidade de pensar e responder a perguntas como as seguintes: no início da tarefa, quais são os objetivos que pretendo conseguir? Quais parâmetros devo levar em conta para resolvê-lo? Que conhecimento é preciso para realizá-lo? Durante a realização da tarefa, estou atingindo os objetivos que pretendo? Os procedimentos que estou usando são adequados? Estou ajustando meu desempenho no momento quando necessário? No final da tarefa eu alcancei os objetivos inicialmente propostos? Se eu recomeçasse quais fases do processo eu modificaria?

Outro requisito mencionado pelos autores e de grande importância na definição do como ser estratégico, é a intencionalidade. Segundo eles, os sujeitos não passam a ser estratégicos de forma espontânea é necessário que tenham a intensão voltada para isso. Os autores salientam que cabe ao indivíduo à decisão em usar os procedimentos de aprendizagem para resolver uma tarefa com um propósito específico, não de forma aleatória, em que o objetivo perseguido nem sempre é o mesmo. Em algumas ocasiões, o interesse pode se concentrar na aquisição de cultura sobre um assunto; em outros, a intenção é aprofundar o conhecimento de um assunto; em outros casos, o propósito pode ser concordar em um ponto de vista, ou especialmente quando se trata do professor, o objetivo é o de ensinar os alunos o que aprendeu.

Essa diversidade de objetivos que o aprendiz enfrenta determinará sua decisão em relação a quais procedimentos de aprendizado serão usados e de que maneira. Se o professor é o aprendiz, especialmente ao executar atividades de aprendizagem, seu desafio será em como ensinar o que aprendeu aos seus alunos. A intencionalidade nesse caso tem um papel 
fundamental na preparação da sua aula, pois, conhecendo as estratégias adequadas, pode propor atividades, ou seja, procedimentos que favoreçam nos alunos o desenvolvimento de tais estratégias.

Para o professor ser estratégico, Monereo et al. (2011) sinalizam que ele precisa aprender sobre como ser estratégico em sua disciplina e como implementar essas estratégias em sala de aula. Para isso é necessário que, na sua formação, desde o nível universitário até a formação continuada, elas sejam desenvolvidas. A formação inicial deve abarcar, além dos conhecimentos específicos da área, instrumentos de interpretação e análise que permitam ao docente a capacidade de refletir sobre sua didática, tomar decisões sobre o seu desempenho como aprendizes e como professores estratégicos, de modo a enriquecer e expandir a formação na interação com a realidade cotidiana da prática profissional.

Sobre o papel do professor em termos de ensinar as estratégias metacognitivas a seus alunos, temos que compreender que ao orientar o desenvolvimento de seus alunos por meio desse processo, ele o faz não só descrevendo as etapas, mas também por meio de suas experiências, normas, valores, técnicas, modos de ação, hábitos e habilidades.

Grangeat (1999) enfatiza que o professor pode desenvolver inúmeras situações que possam estimular o aluno a recorrer a vários métodos e, dessa forma, avaliar suas escolhas. É dessa forma que o aluno, sobretudo aqueles com mais dificuldades, tem a oportunidade de conduzir de maneira refletida suas próprias operações cognitivas. Ainda a respeito disso, Brown (1987) também destaca o papel do professor, ao dizer que ele tem a função de mediador na aprendizagem e age como um promotor da autorregulação, ou seja, deve ensinar o aluno a planejar e monitorar suas atividades.

É significativo que os processos educacionais possam orientar e fomentar habilidades de pensamento nos estudantes, isto é, aprender a aprender e aprender a pensar de forma autônoma, e não apenas acumular conhecimentos sem significado. Como já mencionado, a efetivação desses processos no contexto escolar está fortemente ligada ao papel do professor, que, por meio da sua metodologia de ensino, pode contribuir para que os alunos passem a adotar essa forma de pensamento. Por outro lado, como salientam Monereo et al. (2011), se o trabalho realizado pelo professor não for adequado, pode favorecer o desenvolvimento de um pensamento rígido nos alunos, uma forma mecânica de aprendizagem, ou ainda, transformar-se em dificuldades no aprendizado da disciplina. 
Destacamos, ainda, que a verdadeira aprendizagem é aquela adquirida de forma ativa e consciente, por meio de um sistema de ações e práticas mentais empreendidas pelo aluno e que têm como precedente a orientação do professor. Essa orientação varia quantitativa e qualitativamente ao longo do processo de ensino-aprendizagem, conforme destaca Pérez Cabaní (1995, p. 2, tradução nossa):

\begin{abstract}
A ajuda necessária em cada momento do processo será variável em forma e quantidade. Às vezes, o ajuste da ajuda pedagógica será alcançado, fornecendo ao aluno informações organizadas e estruturadas; em outras ocasiões, oferecendo modelos de ação para imitar, em outros, pedindo instruções e sugestões mais ou menos detalhada para enfrentar o trabalho, ou em outros casos, permitindo-lhe escolher e desenvolver completamente autonomamente a atividade de aprendizagem.
\end{abstract}

Sintetizando o apresentado, Monereo et al. (2011) anuncia algumas orientações que o professor deve realizar para ensinar seus alunos a aprender estratégias de aprendizagem, a saber:

- o professor deve ajudar na análise das operações e decisões mentais tomadas no processo de resolução de uma tarefa, a fim de melhorar os processos cognitivos que os alunos utilizam. Deve orientá-lo a buscar onde e como pesquisar, como selecionar informações relevantes, como elaborar e confirmar uma hipótese, que forma e sob quais critérios organizar e apresentar as informações descobertas, entre outros. Por exemplo, na resolução de um problema de Física, a leitura do enunciado e a identificação dos dados (planificação) durante a resolução (regulação e monitoração) e finalização do problema (avaliação);

- o professor deve explicar as relações existentes entre o conteúdo e a forma como ele é ensinado, oferecendo modelos de aprendizado sobre como aprender o assunto e as relações com o mundo vivencial. Nesse processo, é necessário favorecer o uso estratégico de procedimentos de aprendizagem;

- o professor deve induzir os alunos a pensarem de forma reflexiva sobre os processos de pensamento que utilizam para resolver os problemas propostos na sala de aula, levando em conta as características particulares ou condições em que ocorre, como enunciado do problema e indicações prévias do professor, resultado a ser obtido, palavras-chave do problema, algoritmos e/ou heurísticos de resolução, recursos que podem ser usados, restrições de tempo, etc. Dessa forma, as técnicas de estudo não devem ser apresentadas 
de forma prescritiva, mas por meio de oportunidades em que os alunos possam aplicar estratégias e decidir em que momento e de que modo elas serão realizadas;

- o professor deve propor avaliações que permitam a reelaboração das ideias ensinadas e não apenas a sua repetição. Diferentes estudos mostraram que avalições que propõem uma evolução do que é aprendido afetam muito a forma e a qualidade do estudo e da aprendizagem dos alunos. Esses estudos ainda apontam que testes objetivos parecem favorecer uma aprendizagem mais mecânica e repetitiva, enquanto as avaliações baseadas na resolução de problemas ou na análise de casos facilitam uma aprendizagem mais significativa e abrangente dos conceitos estudados. As avaliações devem ser vistas como uma oportunidade especial para aprender sobre o assunto, a partir da aplicação autônoma das estratégias aprendidas pelo aluno.

Seguem os autores mencionando que essa orientação metodológica busca que o aluno passe a ter cada vez mais autonomia e controle da sua própria aprendizagem. Dessa forma, ensinar os alunos a agir estrategicamente, durante o seu aprendizado, significaria "passar a função reguladora desempenhada pelo professor para autorregular sua aprendizagem, e assim planejar, controlar e avaliar suas operações mentais enquanto aprendem um processo de ensino" (p. 67, tradução nossa).

O esquema elaborado pelos autores está sintetizado no Quadro 3.

Quadro 3: Ensino-aprendizagem do uso de procedimentos.

\begin{tabular}{|c|c|c|c|c|}
\hline + Dependência & \multicolumn{3}{|c|}{ ALUNO/A } & - Dependência \\
\hline $\begin{array}{l}\text { Apresentação } \\
\text { da estratégia }\end{array}$ & $\begin{array}{l}\text { Prática } \\
\text { Guiada }\end{array}$ & $\begin{array}{c}\text { Prática em } \\
\text { contextos } \\
\text { variados }\end{array}$ & $\begin{array}{c}\text { Uso } \\
\text { "Estratégico" }\end{array}$ & $\begin{array}{c}\text { Prática } \\
\text { independente }\end{array}$ \\
\hline $\begin{array}{l}+ \text { Controle da } \\
\text { Atividade }\end{array}$ & & PROFESSOR & & $\begin{array}{l}\text { - Controle da } \\
\text { Atividade }\end{array}$ \\
\hline
\end{tabular}

Fonte: Monereo et al., (2011, p. 67) 
Nesse modelo, o processo de ensino inicia com uma situação de apresentação, em que é explicitada a maneira apropriada de executar um procedimento. Por exemplo, o professor apresentaria métodos para a resolução de um problema como um guia, um passo a passo, em que são empregadas estratégias que poderiam ser usadas para a resolução. De forma gradativa, devem ser apresentadas outras situações, de complexidades maiores, que exijam um aprofundamento do conhecimento cognitivo, estimulando os alunos a avaliar se o procedimento empregado anteriormente poderia ser adequado para essas novas situações. Nessa etapa, é necessário que o aluno possa observar o uso estratégico do procedimento como uma forma condicional e que possa avaliar em que situações é mais ou menos apropriada a sua utilização, ou quais outros procedimentos precisam ser acionados.

Aos poucos, o professor começa a responsabilizar seus alunos pelas decisões que devem ser tomadas ao estender o procedimento para diferentes situações. Isso fará com que seja mais fácil para o aluno generalizar a estratégia para outros tópicos e tarefas de maior complexidade com o mínimo de ajuda do professor. Ao final do processo, a ajuda oferecida pelo professor diminui ou é retirada definitivamente, de modo que o aluno passe a ter autonomia para a prática da estratégia em ambientes de aprendizagem em outras situações.

Essa orientação metodológica sugerida pelos autores leva em consideração que "é o professor, por meio da interação educacional que estabelece na aula, quem vai gradualmente transferindo o controle e a regulação das atividades para seus alunos” (Monereo et al., 2011, p. 68, tradução nossa). Esse trabalho de inserir as estratégias e confrontá-las às diferentes situações deve ser realizado de forma frequente até que estas possam ser internalizadas e utilizadas de forma independente e, em certa medida, até em outras situações que não sejam necessariamente do contexto escolar.

O exposto sobre as estratégias de aprendizagem anunciadas por Monereo et al. (2011) e os respectivos entendimentos sobre o papel e as possibilidades do professor recorrer a elas representam movimentos de natureza metacognitiva, como bem destacado pelo próprio autor em trabalho anterior (2001). Mesmo sem se ater especificamente a elas, os autores dialogam com essa possibilidade à medida que defendem a importância do aluno (ou professor) reconhecer seus conhecimentos, bem como no momento em que devem autorregular sua ação, por meio da planificação, monitoramento e avaliação. Nesse contexto, reconhecemos a importância de que as estratégias utilizadas pelos professores ou pelos alunos em suas 
aprendizagens representam estratégias metacognitivas e podem ser agregadas às diferentes ferramentas didáticas.

Todavia, unimos a essa proposta de Monereo et al. (2011) a etapa de tomada de consciência sobre os próprios conhecimentos ou, como proposto por Flavell (1976), o "conhecimento do conhecimento", uma vez que essa etapa não assume relevância nas discussões do autor, assim como as experiências metacognitivas, particularmente de aspectos como motivação e emoções.

\section{Estratégias metacognitivas: novas possibilidades}

O apresentado por Monereo et al. (2011), embora represente uma perspectiva metodológica interessante e com especificidades que julgamos fundamentais para um ensino por estratégias metacognitivas, foca as ações na parte do controle executivo e autorregulador (planejamento, monitoramento e avaliação), carecendo, em nosso entendimento, ampliá-lo na perspectiva de trazer para o contexto escolar perspectivas que permitam perpassar situações que estimulem o conhecimento metacognitivo, considerando este associado diretamente relacionado às experiências metacognitivas.

Como mencionado por Wang (1983) e McCombs (1988) e apresentado na introdução, o pensamento metacognitivo contribui não apenas para o desenvolvimento de habilidades relacionadas aos processos de controle executivo e autorregulador, mas igualmente para o desenvolvimento da tomada de consciência dos sujeitos sobre seus próprios conhecimentos, considerados por Piaget como fundamentais na construção dos conhecimentos. Tais elementos metacognitivos vem ao encontro do especificado por Flavell e Wellman (1977) sobre os elementos considerados as variáveis que interferem na tomada de consciência do sujeito/estudante sobre seus próprios conhecimentos: pessoa, tarefa e estratégia.

A variável pessoa incluiu os atributos e estados que são importantes para a identificação do conhecimento que o indivíduo possui sobre si mesmo e sobre ele em relação aos outros, especialmente no que diz respeito à recuperação da informação na estrutura cognitiva. De acordo com Flavell e Wellman (1977) e apoiados nos estudos de Flavell sobre a memória, recuperar informações é importante para desenvolver a potencialidade individual de aprendizagem e saber como o sujeito é enquanto aprendiz e em comparação com o outro. A experiência de recuperar informações poderia auxiliar o aluno a lembrar datas e pessoas e formar opinião sobre como 
suas técnicas de recuperação são comparadas às dos demais indivíduos. Outro aspecto que os autores chamam a atenção é que as sensações mnemônicas internas influenciam a lembrança de determinado dado e podem intuir no sujeito que esse dado nunca foi armazenado, mas também pode identificar que ele não é recuperável na memória agora, mas poderá perceber que, se usar algum artifício externo, poderá lembrar. Durante a aprendizagem, a sensação de que algo é difícil de aprender ou a satisfação de poder recuperar uma informação pode lhe proporcionar uma satisfação que auxilia novas aprendizagens (Flavell, \& Wellman, 1977).

De acordo Zohar e Barzilai (2013), o conhecimento sobre a pessoa refere-se ao autoconhecimento daquilo que influencia a atividade cognitiva do indivíduo, o conhecimento da cognição dos outros e o conhecimento da cognição universal das pessoas. Flavell, Miller e Miller (1999) subdividem esse conhecimento em três possibilidades: universal, intraindividual e interindividual. Por universal são entendidos os conhecimentos que os indivíduos apresentam sobre como funciona seu pensamento, ou, conforme mencionado anteriormente, quando não se lembra de algo, mas sabe que pode recuperar essa informação mais tarde. Os intraidividuais são as crenças que os sujeitos apresentam sobre si mesmo, ou seja, quando identifica que precisa anotar algo para lembrar futuramente, porque sabe das limitações de sua memória; por fim, os interindividuais representam os conhecimentos que as pessoas têm sobre elas em comparação com o outro, isto é, quando identifica que é melhor resolvedor de problemas em Física que seu colega, enquanto ele é melhor nas discussões teóricas.

A segunda variável que integra o conhecimento metacognitivo é a tarefa que está associada às diferentes naturezas que as tarefas apresentam, ou seja, algumas são mais fáceis de serem lembradas e outras mais difíceis. Aspectos mais próximos a situações vivenciadas, próximas ao sujeito, são mais fáceis de serem recuperáveis na estrutura cognitiva; outras, entretanto, carecem de mais esforços para serem recuperadas e, algumas vezes, não são. Como exemplo dessas últimas, pode-se mencionar conteúdos distantes que, por alguma razão, são necessários para a aprendizagem. Tais conteúdos dificilmente representam uma tarefa fácil de serem lembrados e pode ser necessário um processo intermediário para que eles sejam recuperados na estrutura cognitiva da pessoa. Sobre isso Flavell e Welmann (1977) mencionam que a tarefa de recuperar informações mais distantes pode ser favorecida quando for criada uma história com links entre elas, isso favorecerá a sua recuperação. Portanto, a variável tarefa está 
relacionada a dois tipos: as que estão vinculadas à natureza do conhecimento a ser recuperado e as que estão vinculadas às exigências que essa recuperação poderá requerer.

Flavell, Miller e Miller (1999, p. 127) exemplificam cada um dos dois tipos relatando que o primeiro se refere ao caso de que "você sabe, por experiência própria, que informações complexas e estranhas tendem a ser difíceis e trabalhosas de compreender e lembrar"; enquanto o segundo tipo estaria mais próximo da situação em que "você sabe que é mais fácil recordar a ideia geral de uma história do que suas palavras exatas".

Como terceiro elemento do conhecimento metacognitivo, Flavell e Wellman (1977) mencionam a variável estratégia, que está vinculada às táticas que o sujeito utiliza para recuperar as informações em sua estrutura cognitiva. Mais especificamente, está associada à identificação de "quando", "como" e "por que" utilizar tal estratégia para recuperar a informação. Os autores inferem haver estratégias que "podem servir para preparação de uma futura recuperação e estratégias que podem facilitar a presente recuperação" (Flavell, \& Wellman, 1977, p. 19, tradução nossa). Portanto, a variedade de estratégias e os movimentos que o indivíduo faz para recuperar conhecimentos são variados e estão associados ao que se deseja recuperar ou ativar.

Flavell, Miller e Miller (1999) relatam que essa variável do conhecimento se encontra associada às diferentes possibilidades para recordar um fato ou para resolver um problema; o sujeito, diante dessas possibilidades, acaba estabelecendo critérios próprios para selecionar a estratégia que melhor lhe convém. Para exemplificar, os autores relatam que os sujeitos recorrem a um tipo de estratégia para recordar números de telefones e a outras mais sofisticadas para estudar "materiais mais importantes ou menos familiares do que materiais menos importantes e já aprendidos” (FLAVELL; MILLER; MILLER, 1999, p. 127).

A descrição das três variáveis permite retomar o trabalho de Monereo et al. (2011) e enfatizar a importância de incluir esses elementos como forma de oportunizar uma qualificação no processo ensino-aprendizagem, particularmente daqueles que declaradamente não se apoiam nessa possibilidade em suas ações de aprendizagem escolar. Essa associação foi avaliada em um estudo sobre a viabilidade de uma proposta didática em Física envolvendo as atividades experimentais (Rosa, 2011). No estudo, foi elaborado um modelo de atividades experimentais na orientação metacognitiva denominado “Atividades Experimentais Metacognitivas” (AEMc) que envolvia as três variáveis anunciadas por Flavell e Wellman (1977) somada as três 
discutidas por Brown (1978) e igualmente assinaladas por Monereo et al. (2011) como integrantes das estratégias metacognitivas. O modelo desenvolvido foi aplicado com um grupo de estudantes do ensino médio e os resultados foram promissores, tanto em termos da viabilidade didática, como na retenção dos conhecimentos. Como avaliação do modelo proposto, a autora enfatiza a importância dele para aprendizagem em Física, mas menciona a dificuldade de os estudantes distinguirem em suas ações os elementos estratégia e planificação e em executar o monitoramento. Tais limitações são atribuídas a falta de hábito dos estudantes em refletir sobre seus próprios conhecimentos e ações.

\section{Considerações finais}

O texto se ocupou de relatar aspectos vinculados a utilização da metacognição no contexto da educação científica, por meio, de uso de estratégias metacognitivas. Nessa retomada foi apresentado algumas variações associadas ao entendimento de metacognição, a diferenciação entre os domínios cognitivos e metacognitivos, o entendimento das estratégias metacognitivas e descrita uma possibilidade de ampliar o defendido nos estudos de Monereo e colaboradores.

Retomando o objetivo do texto temos que o estudo mostrou aspectos que precisam ser considerados no momento em que o professor deseja incluir estratégias metacognitivas associadas as ações didáticas. Dentre esses enfatizou a necessidade de o professor recorrer a essas estratégias no momento em que prepara suas atividades, demonstrando aos estudantes que faz uso desse tipo de estratégia. Além disso, Monereo e colaboradores inferem que o professor deve servir explicitar o uso dessas estratégias de modo que os alunos as compreendam no contexto das matérias e conteúdos escolares. Ao exposto o texto acrescenta a necessidade de revisitar a proposta dos autores de modo a incluir aspectos vinculados a tomada de consciência dos estudantes em relação aos seus próprios conhecimentos, na perspectiva do que Flavell (1976) denomina de "conhecimento metacognitivo". Nessa perspectiva, as estratégias metacognitivas estariam associadas a um momento anterior a realização das atividades (etapa de operacionalização ou execução da ação) e vinculada a discussão sobre as variáveis que vão influenciar o desempenho do estudante na concretude de seu objetivo. Tais variáveis estão associadas ao proposto por Flavell e Wellman (1977) e operacionalizadas no contexto do ensino de Física por Rosa (2011): pessoa, tarefa e estratégia. 
Por fim e como continuidade do estudo, propomos ampliar o número de estudos buscando uma compreensão consensual de metacognição e que as estratégias metacognitivas a partir desse novo incremento, possam ser analisadas em novos estudos vinculados a sala de aula, fornecendo mais elementos para que possamos ter avanços significativos no campo da metacognição.

\section{Referenciais bibliográficos}

Brown, A. L. (1978). Knowing when, where, and how to remember: a problem of metacognition. In R. Glaser (Org.), Advances in instructional psychology (pp. 77-165). NJ: LEA.

Brown, A. L. (1987). Metacognition, executive control, self-regulation, and other more mysterious mechanisms. In F. E. Weinert, R. H. Kluwe (Eds.). Metacognition, motivation and understanding (pp. 65-116). Hillsdale, New Jersey: Lawrence Erlbaum Associates.

Campanario, J. M., \& Otero, J. (2000). Más allá de las ideas previas como dificultades de aprendizaje: las pautas de pensamiento, las concepciones epistemológicas y las estrategias metacognitivas de los alumnos de ciencias. Enseñanza de las Ciencias, 18(2), 155-169.

Chan, C. K. (2012). Co-regulation of learning in computer-supported collaborative learning environments: A discussion. Metacognition and learning, 7(1), 63-73. https://doi.org/10.1007/s11409-012-9086-Z

Chi, M. T., Glaser, R., \& Rees, E. (1982). Expertise in problem solving. In R. J. Sternberg (Org.). Advances in the psychology of human intelligence. v. 1 (pp. 7-75). Hilsdale, N.J.: Erlbaum.

Correa, N. N. G., Passos, M. M., Arruda, S. M. (2017) Perfil Metacognitivo (parte I): uma proposta de instrumento de análise. Investigações em Ensino de Ciências, 22(3), 176191. http://dx.doi.org/10.22600/1518-8795.ienci2017v22n3p176

Correa, N. N. G., Passos, M. M., Arruda, S. M. (2018) Perfil Metacognitivo (parte I): aplicação de instrumento de análise. Investigações em Ensino de Ciências, 23(1), 230-244. http://dx.doi.org/10.22600/1518-8795.ienci2018v23n1p230

Efklides, A. (2006). Metacognition and affect: What can metacognitive experiences tell us about the learning process? Educational Research Review, 1(1), 3-14. https://doi.org/10.1016/i.edurev.2005.11.001

Figueira, A. P. C. (2006). Estratégias cognitivo/comportamentais de aprendizagem: problemática conceptual e outras rubricas. Revista Iberoamericana de Educación, 37(6).

Flavell, J. H. (1971). First discussant's comments: what is memory development the development of? Human Development, 14(4), 272-278. https://doi.org/10.1159/000271221 
Flavell, J. H. (1976). Metacognitive aspects of problem solving. In L. B. Resnick (Ed.). The nature of intelligence (pp. 231-236). NJ: LEA.

Flavell, J. H, \& Wellman, H. (1977). Metamemory. In R. V. Kail, \& J. W. Hagen (Eds), Perspectives on the development of memory and cognition (pp. 3-33). NJ: LEA.

Flavell, J. H. (1979). Metacognition and cognitive monitoring. American Psychologist, 34(10), 906-911. http://dx.doi.org/10.1037/0003-066X.34.10.906

Flavell, J. H., Miller, P. H., \& Miller, S. A. (1999). Desenvolvimento cognitivo. Tradução de Cláudia Dornelles. 3. ed. Porto Alegre: Artes Médicas Sul, 1999.

Formica, S. P., Easley, J. L., \& Spraker, M. C. (2010). Transforming common-sense beliefs into Newtonian thinking through Just-In-Time Teaching. Physical Review Special TopicsPhysics Education Research, 6(2), 020106.

Hacker, D. J. (1998). Definitions and empirical foundations. In J. D. Hacker, J. Dunlosky, \& A. Graesser. Metacognition in educational theory and practice (pp. 1- 23). Mahwah, New Jersey: Lawrence Erlbaum Associates.

Hennessey, G. (2003). Metacognitive aspects of students' reflective discourse: Implications for intentional conceptual change teaching and learning. In G. Sinatra \& P. Pintrich (Orgs.), Intentional conceptual change (pp. 103-132). Mahwah, NJ: LEA.

Hinojosa, J., \& Sanmartí, N. (2016). Promoviendo la autorregulación en la resolución de problemas de física. Ciência \& Educação, 22(1), 7-22. http://dx.doi.org/10.1590/1516$\underline{731320160010002}$

Malone, K. L. (2008). Correlations among knowledge structures, force concept inventory, and problem-solving behaviors. Physical Review Special Topics - Physics Education Research, 4(2), 020107-1-15. https://doi.org/10.1103/PhysRevSTPER.4.020107

Mayor, J., Suengas, A., \& González Marqués, J. (1995). Estratégias metacognitivas: aprender a aprender e aprender a pensar. Madrid: Síntese.

Monereo, C. (2001). La enseñanza estratégica: enseñar para la autonomía. In C. Monereo (Org.). Ser estratégico y autónomo aprendiendo (pp. 11-27). Barcelona: Graó.

Mota, A. R., \& Rosa, C. T.W. (2018). Ensaio sobre metodologias ativas: reflexões e propostas. Revista Espaço Pedagógico, 25(2), 261-276.

Muñoz, Á. V. (2017) ¿Qué hay de nuevo en la metacognición? Una revisión del concepto y su aplicación en los procesos de lectura y escritura. Venezuela. Recuperado de https://www.researchgate.net/publication/306079274

Nelson, T., \& Narens, L.(1994). Why investigate metacognition. In M. Janet, \& A. Shimamura (Org). Metacognition: Knowing about knowing (pp. 1-25). Cambrigde: ABB.

Noël, B. (1991). La métacognition. Bruxelles: De Boeck Université.

Peters, E. E. (2012). Developing content knowledge in students through explicit teaching of the nature of science: Influences of goal setting and self-monitoring. Science \& Education, 21(6), 881-898. https://doi.org/10.1007/s11191-009-9219-1 
Pintrich, P. R., Wolters, C. A., \& Baxter, G. P. (2000). Assessing metacognition and selfregulated learning. In G. Schraw, \& J. C. Impara (Orgs.), Issues in the measurement of metacognition (pp. 43-97). Lincoln, NE: Buros Institute of Mental Measurement.

Pol, H. J., Harskamp, E. G., Suhre, C. J., \& Goedhart, M. J. (2009). How indirect supportive digital help during and after solving physics problems can improve problem-solving abilities. Computers \& Education, 53(1), 34-50. https://doi.org/10.1016/j.compedu.2008.12.015

Pozo, J. I., \& Crespo, G. M. A (2006). Aprender y enseñar ciencia: del conocimiento cotidiano al conocimiento científico. Ediciones Morata. Madrid.

Reif, F., \& Larkin, Jill H. (1991). Cognition in scientific and everyday domains: comparison and learning implications. Journal of Research in Science Teaching, 28(9), 733-760.

Rosa, C. T. W. (2011). A metacognição e as atividades experimentais no ensino de Física. (Tese de Doutorado). Universidade Federal de Santa Catarina, Florianópolis.

Rosa, C. T. W., \& Pinho-Alves, J. (2013). Metacognição e as atividades experimentais: aproximações teóricas. Ensaio: Pesquisa em Educação em Ciências, v. 15(1), 95-111.

Rosa, C. T. W. (2014). Metacognição no ensino de Física: da concepção à aplicação. Passo Fundo: Editora da Universidade de Passo Fundo.

Ryan, Q. X., Frodermann, E., Heller, K., Hsu, L., \& Mason, A. (2016). Computer problemsolving coaches for introductory physics: Design and usability studies. Physical Review Physics Education Research, 12(1), 0101051-17. https://doi.org/10.1103/PhysRevPhysEducRes.12.010105

Taasoobshirazi, G., \& Farley, J. (2013a). Construct validation of the physics metacognition inventory. International Journal of Science Education, 35(3), 447-459. https://doi.org/10.1080/09500693.2012.750433

Taasoobshirazi, G., \& Farley, J. A. (2013b). Multivariate Model of Physics Problem Solving. Learning and Individual Differences, 24, 53-62. https://doi.org/10.1016/j.lindif.2012.05.001

Veenman, M. V. J. (2005). The assessment of metacognitive skills: What can be learned from multimethod designs? In C. Artelt, \& B. Moschner (Orgs), Lernstrategien und Metakognition: Implikationen für Forschung und Praxis (pp. 75-97). Münster: Waxmann.

Veenman, M. V. J. (2011). Learning to self-monitor and self-regulate. In R. E. Mayer \& P. A. Alexander (Orgs.), Handbook of research on learning and instruction (pp. 197-218). NY: Routledge.

Veenman, M. V. J., Kok, R., \& Blöte, A. W. (2005). The relation between intellectual and metacognitive skills in early adolescence. Instructional Science, 33(3), 193-211. http://doi.org/10.1007/s11251-004-2274-8

Veenman, M. V. J., van Hout-Wolters, B. H. A. M., \& Afflerbach, P. (2006). Metacognition and learning: Conceptual and methodological considerations. Metacognition and Learning, 1(1), 3-14. https://doi.org/10.1007/s11409-006-6893-0 
Zohar, A. \& Barzilai, S. (2013). A review of research on metacognition in science education: current and future directions. Studies in Science Education, 49(2), 121-169. https://doi.org/10.1080/03057267.2013.847261

\section{Autores/as}

Cleci Teresinha Werner da Rosa. http://orcid.org/0000-0001-9933-8834. Universidade de Passo Fundo; Brasil. Doutora em Educação Científica e Tecnológica Docente no Programa de Pós-Graduação em Educação Docente no Programa de Pós-Graduação em Ensino de Ciências e Matemática Docente do Curso de Física-L

Marivane de Oliveira Biazus. https://orcid.org/0000-0003-4394-7061. Universidade de Passo Fundo; Brasil. Doutorando em Educação na Universidade de Passo Fundo; Mestre em Ensino de Ciências e Matemática; Professora de Física na Universidade de Passo Fundo Curso de Física-L 